few rare cases, where, apparently from an oblique and high opening in the membranes, discharges, such as you so accurately describe, came on for months before delivery; and yet all went ultimately well for both mother and child. Four out of six, however, end in premature labour." I felt afraid that another discharge of blood might occur at a month's interval from the last attack, and therefore watched the patient carefully at this time. Just exactly the day month from the former hæmorrhage (six months of pregnancy), I found her pulse quick, and face flushed, buit with no uneasiness or idea that anything unusual was to happen. I ventured to predict that there would be either a return of the hæmorrhage or a miscarriage that night. In about an hour afterwards, labour came on, and she was delivered of a six months' fotus. The amniotic sac was felt, as usual, full and tense, requiring rupture, after which a large quantity of amniotic fluid escaped. During all this time, I kept my patient in bed. The fluid in this case could not have been amniotic, as, from its continuance and profuseness, labour must have come on sooner, while the presence of the sac entire at labour requiring to be ruptured proved it.

At the next pregnancy, at about the corresponding period of advance in gestation, the same fluid again came away in the middle of the night in a gush. Having found on the former occasion that no effect in warding off the miscarriage was produced by keeping the patient in bed, I allowed her to rise, but requested her to keep the sofa for a week. At the end of this period, the discharge recurred as before. She then rose and went about as usual, but there was no further return of the discharge, and she went safely to term. She is at present pregnant a third time, and a third time has the discharge come on at the same period of pregnancy as at first. This time, the patient would not even keep the sofa for a clay, and there has been no return of the discharge. This is more than four months ago. There had been no exertion or fatigue to account for the last discharge.

\section{RUPTURE OF THE HEART.}

\section{By W. WINN WESTCOTT, M.B.Lond., Martock.}

S. V., aged 65, married, a carpenter, and a man of good general health and strength, in the summer of 187 I was struck on the forehead by the accidental recoil of an iron bar. This inflicted a wound which injured the temporal artery, and was followed by very free hæmorrhage. Last December, when returning home intoxicated from a neighbouring village, he fell over a bridge and struck his forehead against a sunken stone, inflicting a wound almost identical in position with the former. This wound also caused free hæmorrhage, which was stopped with considerable difficulty. Although not an habitual drunkard, he had drunk freely for many years, and was much shaken in health by the latter accident.

On February 26th, he was at a pullic-house during the evening, in his usual health, and drank moderately, returning home sober. The next morning, he got up feeling unwell, and walked to my surgery, about two hundred yards. As I was not up, he walked home again, and at 9 o'clock I went to see him. He was sitting by the fire, looking weak and ill; and presented very much the appearance of a man who had been iritoxicated overnight. He complained of pain at the epigas. trium and in the region of the stomach, of want of appetite, weakness, and chilliness. The bowels were constipated ; pulse weak, but regular tongue foul. I ordered two tablespoonfuls of the following mixture to be taken three times a day : Bo Spt. æetheris sulph. $3 \mathrm{ij}$; tinct. calumbre

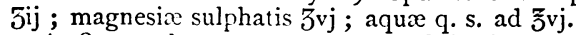

At 8 P.M., he appeared very much in the same state, but complained of nausea and severe pain over the stomach; yet he was lying quietly in bed, with features calm and pale. An hour later, he vomited much bilious matter and semi-digested food. The sickness then went off, and he took a basin of gruel. He expressed himself as feeling better, and his wife went to bed. In a short time, he roused his wife, asking her to make him some peppermint-tea. She did so, and he drank the tea. His wife then returned to bed, between 2 and 3 A.M. Some time later, he sat up in bed, put out the lamp which had been left burning by the bedside, and lay down again. Within ten minutes, he sat up, complained of feeling faint, and again lay down. His wife heard a slight rattling in his throat, upon which she got out of bed, struck a light, and found him dead.

Post Mortim Ixamination, thirty-one hours after death. - The body was well nourished ; the flesh firm. There was a thick layer of fat. The expression of the face was very much altered. There were two linear depressed scars over the lower part of the sternum. The stomach was congested, especially at the cardiac end. The liver was healthy; the splcen and kidneys were congested. The sternum was care- fully raised, without injury to the pericardium, which projected and seemed full and tense. The lungs were pale and normal. The pericardium was opened longitudinally, and about half a pint of serum escaped, leaving a teacupful of soft dark clot. The surfaces of the pericardium were healthy. The heart was removed entire ; and a very considerable deposit of fat on the surface and in the grooves of the organ was noticed. On the wall of the left ventricle, near the anterior border, were three longitudinal fissures : the two upper and smaller ones ex. tended through the pericardium and fatty layer only; the lowest and most anterior extended through the entire thickness of the wall, and measured rather over a quarter of an inch in length, and admitted a goose-quill easily. Internally, all the cavities were healthy, except the left ventricle; and all the valves appeared normal. The left ventricle was opened through the septum of the ventricle, and was found to contain soft dark clots, interlaced with the chordæ tendineæ and columnæ carnex. The clots were gently washed away by water; there were then seen several of the musculi papillares, ruptured, and their free ends covered by slight clots; and, near the anterior border, a long ragged zigzag fissure, three-quarters of an inch in length, corresponding to the principal external rupture ; its edges were also covered by small clots, but there was no continuous clot in the course of the wound. Several portions of the muscular substance were examined by the microscope, and were found to have undergone fatty degeneration.

\section{ILLUSTRATIONS OF SURGICAL DIAGNOSIS.}

\section{BY JOHN GRANTHAM, F.R.C.S., Crayford, Kent.}

Ar the district meeting of the South-Eastern Branch at Dartford, on April 24th, 1863, I read a paper on the necessity of comparative ob. servation in the investigation of injuries. The paper was published in the BRITISH MEDICAL JOURNAL for June 20 th of that year. The following case further supports my argument.

On August $\eta$ th, I87r, I was sent for to see Mr. E. W., who was suffering from an attack of colic. On the following day, he called my. attention to his inability to walk on the left leg without great pain, attended with impeded movement of the ankle-joint. This had been ascribed to some disease of the veins, but the patient considered it to be the effect of rapid mounting and dismounting. The narrative he gave of himself was: "On the morning of the Ist May, I867, at about two. o'clock, I was awoke with a sharp pain in my left groin. I struck a light and attempted to get out of bed (being at this time in the army at Athlone, Ireland), but found I could not stand, and that my left leg was immensely swollen. At eight o'clock I was assisted into the hospital, when I was treated for rheumatism, and had my leg bandaged with wadding and flannel. I was kept to my bed, when about a fortnight elapsed, and the pain did not decrease. Six leeches were applied to my groin, and the bandage was left off. After this, blisters were applied; my leg at this time being kept bandaged. After the blistering, iodine was used to paint my groin with. I was still kep? confined to my bed, with my leg elevated and bandaged. This treatment continued till the latter end of July, when my leg was rubbed with a lotion, and continued till the 16 th of August. All this time numerous doctors visited me, and could not give a name to my com. plaint. In September, I was allowed to walk a little, and continued till February, when I was put forward for discharge as incurable in ward. I may state the pain left my groin about the middle of August, and my veins in the abdomen took to swelling, and they have kept swollen since that time. Two men of great eminence in London saw me, and said it was one of those hidden complaints which were beyond human control."

On examination, I found the leg odematous, the heel elevated, and the flexor tendon on the fore part of the ankle-joint tense. On comparing the form and size of the gastrocnemius muscle of the injured leg with the one not injured, I found the muscular portion diminished in size, with evident division of the lower part next to the origin of the tendo Achillis. The foot was inverted so as to represent the appearance of a case of talipes varus. I diagnosed it to be rupture of the muscular part of the gastrocnemius, with partial dislocation of the anklejoint forward, as the foot could not be flexed, the joint being fixed. Regarding the case as one of partial dislocation, I made forcible extension for a time, until I perceived an audible movement of the lower or tarsal extremity of the tibia. I then suddenly flexed the foot to an acute angle with the tibia, which enabled him to move the joint in every direction. I then ordered hot fomentations, with perfect rest, for three days; at the end of which time he could walk on an even surface without any pain. After the three days' rest, the split or depression could very clearly be defined. On February 26 th, he resumed his duties as a railway 